\title{
Development of Identification Tools for Distinguishing Different Coriander (Coriandrum sativum L.) Genotypes Based on its Stem and Branches Characteristics
}

\author{
Amit*, T.P. Malik and S.K. Tehlan \\ Department of Vegetable Science, CCS, Haryana Agricultural University, \\ Hisar-125 004, India \\ *Corresponding author
}

\section{Keywords \\ Coriander, \\ Genotype, Stem, Characterization, Identification \\ Article Info \\ Accepted: \\ 07 March 2019 \\ Available Online: \\ 10 April 2019}

\section{A B S T R A C T}

An experiment was undertaken to categorise the coriander genotypes based on visual morphological diagnosis. The investigation was carried out at research farm area of department of vegetable science, Chaudhary Charan Singh Haryana Agricultural University, Hisar during the year 2011-2012. Sixty genotypes of coriander obtained from the Department of Vegetable Sciences were studied for the experiment, the seeds of all the genotypes were sown in Augmented block design (ABD) in four blocks with 15 entries in each block along with 4 checks (DH-5 = Hisar Anand, DH-36 = Hisar Sugandh, DH-228 = Hisar Bhoomit and DH-246 = Hisar Surbhi) randomized with in block with single row of $3.0 \mathrm{~m}$ length at spacing of $50 \times 20 \mathrm{~cm}$ within each row. Plant morphological parameters i.e. stem pubescence, stem colour, streaks on stem and number of primary and secondary branches per plant of all sixty genotypes was recorded for categorization. It was found from the results that out of total sixty genotypes, maximum genotype's stem were pubescence, purple in colour and were more branched in terms of primary and secondary branches. These parameters showed wide divergence and hence these can be used as varietal identification.

\section{Introduction}

Coriander is an annual spice herb that belongs to the family of Apiaceae. It is used as a spice in culinary, medicine (Kubo et al., 2004; Delaquis et al., 2002) perfumery, food, beverage, and pharmaceuticals industries. The dried fruits are known as coriander or coriandi seeds. In India they are called dhania. The seeds are described as warm, nutty, spicy, and orange-flavoured. The seed contains significant quantities of carotene, thiamine, riboflavin, niacin, tryptophen, vitamin $\mathrm{B} 6$, vitamin $\mathrm{C}$ and $\mathrm{E}$ (Holland et al., 1991) iron, manganese, magnesium and dietary fiber to the diet. It is highly reputed ayurvedic medicinal plant commonly known as "Dhanya" in India. This plant is highly aromatic and has multiple uses in food and in other industries. India is the biggest producer, consumer and exporter of coriander in the world with an annual production of around three lakh tonnes. It is an annual, herbaceous plant which originated from the 
Mediterranean and Middle Eastern regions and known as medicinal plants. It contains an essential oil (0.03 to 2.6\%) (Nadeem et al., 2013) The green herb is employed for the preparation of either steam-distilled essential oil or the solvent extracted oleoresin (Nadia and Kandi, 2012). Coriander has been reported to posses many pharmacological activities like antioxidant (Darughe et al., 2012), anti-diabetic (Eidi et al., 2012), antimutagenic (Cortes et al., 2004), anti-lipidemic (Sunil et al., 2012), anti-spasmodic (Alison et al., 1999).

The continued development of new varieties is cornerstone of increase in crop yield and productivity in agriculture. Availability of crop germplasm is a basic requirement for the genetic improvement of crops. Genotype has desirable traits in respect to yield, quality, biotic and abiotic stress resistance. Scientists must identify such genotypes having such desirable traits. The systematic record consists of genotype characters which can be obtained by characterization. Although the genotypes are available, adequate characterization for agronomic and morphological traits is necessary to facilitate utilization by plant breeders. Characterization is used to distinguish the genotypes on the basis of their highly heritable characters that help to select the most suitable genotypes according to the needs of user/Plant Breeders.

According to a recent IBPGR definition, characterization consists of recording those characters which are highly heritable, can be easily seen by the eye and are expressed in all environments. Characterization should provide a standardized record of readily assessable plant characters.

This needs to be distinguished from preliminary evaluation, which is the recording of a limited number of agronomic traits considered to be important in crop improvement. Germplasm characterization is carried out in precision fields by spaced planting under adequate agronomic conditions and plant protection. For each accession several morpho-agronomic traits are recorded using the descriptors. Descriptors of genotypes of crop species are required for varietal identity, determining varietal purity, establishing the distinctness of the new genotypes from existing varieties and documentation of genetic resources.

\section{Materials and Methods}

The present study was undertaken for categorization of coriander genotypes based on its stable-morphological visual diagnostics. The investigation was carried out at research farm area of department of vegetable science, Chaudhary Charan Singh Haryana Agricultural University, Hisar during the year 2011-2012. Sixty genotypes of coriander obtained from the Department of Vegetable Sciences were studied for the experiment, the seeds of all the genotypes were sown in Augmented block design (ABD) in four blocks with 15 entries in each block along with 4 checks $(\mathrm{DH}-5=$ Hisar Anand, DH-36 = Hisar Sugandh, DH-228 = Hisar Bhoomit and DH-246 = Hisar Surbhi) randomized with in block with single row of $3.0 \mathrm{~m}$ length at spacing of $50 \times 20 \mathrm{~cm}$ within each row. In the study, plant morphological parameters were identified which can be used to categorised the coriander genotypes.

During the course of experiment, plant morphological parameters i.e. Stem pubescence were recorded by noticed the stem surface visually whether the surface is smooth or pubescent; Stem colour was observed visually whether the stem is green or purple and on the basis of data recorded genotypes were categorized in green colour or purple colour of stem; Streaks on stem was observed visually whether streak on the stem 
was present or not; Number of primary branches per plant (i.e. branch arises from the main stem) was recorded and genotypes were characterized into more branched $(\geq 10)$, less branched $(<10)$ and the number of secondary branches (i.e. branch arises from the primary branches) was recorded by manually counting the secondary branches and genotypes were categorized into less branched $(<20)$ and more branched $(\geq 20)$.

\section{Results and Discussion}

In the present research work it was noticed that there was a great variation in the 60 genotypes on the basis of stem characteristics i.e. stem pubescence, stem colour and streaks on stem. Data of stem characteristics are presented in Table 1 shows that in 45 genotypes stem pubescence were present and 15 genotypes were not having stem pubescence.

Table.1 Categorization of coriander genotypes based on stem characteristics

\begin{tabular}{|c|c|c|c|}
\hline Characteristics & Category & $\begin{array}{l}\text { Number } \\
\text { of entry }\end{array}$ & Genotypes \\
\hline \multirow[t]{2}{*}{$\begin{array}{c}\text { Stem } \\
\text { pubescence }\end{array}$} & $\begin{array}{c}\text { Pubescence } \\
\text { Present }\end{array}$ & 45 & $\begin{array}{l}\text { DH-237-1, DH-239-1, DH-242, DH-242-1, DH-244, DH- } \\
\text { 252, DH-254, DH-258, DH-260, DH-261, DH-268, DH- }-27 \text { - 275, DH-276, DH-276-1, DH-277, DH-278, DH-279 } \\
\text { DH-280, DH-280-1, DH-281, DH-281-1, DH-283-2, DH- } \\
\text { 287, DH-288, DH-289, DH-290, DH-291, DH-292, DH- } \\
\text { 293, DH-293-1, DH-293-2, DH-294, DH-294-1, DH-294- } \\
\text { 2, DH-295, DH-296, DH-297, DH-297-1, DH-298, DH- } \\
\text { 301, DH-302, DH-303, DH-303-1, DH-303-2, DH-304. }\end{array}$ \\
\hline & $\begin{array}{c}\text { Pubescence } \\
\text { Absent }\end{array}$ & 15 & $\begin{array}{l}\text { DH-238, DH-238-1, DH-239, DH-239-2, DH-239-3, DH- } \\
\text { 240, DH-240-1, DH-244-1, DH-244-2, DH-282, DH-283, } \\
\text { DH-283-1, DH-284, DH-286, DH-297-2. }\end{array}$ \\
\hline \multirow[t]{2}{*}{ Stem colour } & Green & 26 & $\begin{array}{l}\text { DH-239-1, DH-239-2, DH-239-3, DH-240-1, DH-242, } \\
\text { DH-242-1, DH-258, DH-260, DH-268, DH-275, DH-277, } \\
\text { DH-278, DH-280, DH-280-1, DH-281, DH-281-1, DH- } \\
\text { 291, DH-293, DH-293-2, DH-294-1, DH-294-2, DH-295, } \\
\text { DH-297-1, DH-301, DH-303-1, DH-303-2. }\end{array}$ \\
\hline & Purple & 34 & $\begin{array}{l}\text { DH-237-1-2, DH-238, DH-238-1, DH-239, DH-240, DH- } \\
\text { 244, DH-244-1, DH-244-2, DH-252, DH-254, DH-261, } \\
\text { DH-276, DH-276-1, DH-279, DH-282, DH-283, DH-283- } \\
\text { 1, DH-283-2, DH-284, DH-286, DH-287, DH-288, DH- } \\
\text { 289, DH-290, DH-292, DH-293-1, DH-294, DH-296, } \\
\text { DH-297, DH-297-2, DH-298, DH-302, DH-303, DH-304. }\end{array}$ \\
\hline \multirow[t]{2}{*}{$\begin{array}{l}\text { Streaks on the } \\
\text { stem }\end{array}$} & Present & 30 & $\begin{array}{l}\text { DH-237-1-2, DH-239, DH-242, DH-242-1, DH-244, DH- }-2 \text { - } 252, \text { DH-261, DH-268, DH-276-1, DH-278, DH-279, } \\
\text { DH-280-1, DH-281-1, DH-282, DH-283, DH-284, DH- } \\
\text { 286, DH-288, DH-292, DH-293, DH-293-1, DH-293-2, } \\
\text { DH-295, DH-296, DH-297, DH-297-1, DH-298, DH-301, } \\
\text { DH-302, DH-303-2. }\end{array}$ \\
\hline & Absent & 30 & $\begin{array}{l}\text { DH-238, DH-238-1, DH-239-1, DH-239-2, DH-239-3, } \\
\text { DH-240, DH-240-1, DH-244-1, DH-244-2, DH-254, DH- } \\
\text { 258, DH-260, DH-275, DH-276, DH-277, DH-280, DH- } \\
\text { 281, DH-283-1, DH-283-2, DH-287, DH-289, DH-290, } \\
\text { DH-291, DH-294, DH-294-1, DH-294-2, DH-297-2, DH- } \\
\text { 303, DH-303-1, DH-304. }\end{array}$ \\
\hline
\end{tabular}


Table.2 Categorization of coriander genotypes based on branches per plant

\begin{tabular}{|c|c|c|c|}
\hline Characteristics & Category & $\begin{array}{l}\text { Number } \\
\text { of entry }\end{array}$ & Genotypes \\
\hline \multirow[t]{2}{*}{$\begin{array}{l}\text { Primary } \\
\text { branches }\end{array}$} & $\begin{array}{c}\text { More } \\
\text { branched } \\
(\geq 10)\end{array}$ & 35 & $\begin{array}{l}\text { DH-237-1-2, DH-238, DH-238-1, DH-239-1, } \\
\text { DH-239-2, DH-239-3, DH-240, DH-240-1, } \\
\text { DH-242, DH-244, DH-244-1, DH-258, DH- } \\
\text { 260, DH-261, DH-268, DH-277, DH-279, } \\
\text { DH-280, DH-280-1, DH-281, DH-281-1, DH- } \\
\text { 282, DH-283, DH-283-1, DH-283-2, DH-284, } \\
\text { DH-286, DH-287, DH-288, DH-289, DH-290, } \\
\text { DH-293-2, DH-294, DH-297, DH-303. }\end{array}$ \\
\hline & $\begin{array}{c}\text { Less } \\
\text { branched } \\
(<10)\end{array}$ & 25 & $\begin{array}{l}\text { DH-239, DH-242-1, DH-244-2, DH-252, DH- } \\
\text { 254, DH-275, DH-276, DH-276-1, DH-278, } \\
\text { DH-291, DH-292, DH-293, DH-293-1, DH- } \\
\text { 294-1, DH-294-2, DH-295, DH-296, DH-297- } \\
\text { 1, DH-297-2, DH-298, DH-301, DH-302, DH- } \\
\text { 303-1, DH-303-2, DH-304. }\end{array}$ \\
\hline \multirow[t]{2}{*}{$\begin{array}{l}\text { Secondary } \\
\text { branches }\end{array}$} & $\begin{array}{c}\text { More } \\
\text { branched } \\
(\geq 20)\end{array}$ & 41 & $\begin{array}{l}\text { DH-237-1-2, DH-238, DH-238-1, DH-239, } \\
\text { DH-239-1, DH-239-2, DH-239-3, DH-240, } \\
\text { DH-240-1, DH-242, DH-244, DH-244-1, DH- } \\
\text { 244-2, DH-254, DH-258, DH-260, DH-261, } \\
\text { DH-268, DH-277, DH-278, DH-279, DH-280, } \\
\text { DH-280-1, DH-281-1, DH-283-1, DH-283-2, } \\
\text { DH-284, DH-286, DH-287, DH-288, DH-289, } \\
\text { DH-290, DH-291, DH-292, DH-293, DH-293- } \\
\text { 1, DH-293-2, DH-294, DH-294-1, DH-297-1, } \\
\text { DH-303. }\end{array}$ \\
\hline & $\begin{array}{l}\text { Less } \\
\text { branched } \\
(<20)\end{array}$ & 19 & $\begin{array}{l}\text { DH-242-1, DH-252, DH-275, DH-276, DH- } \\
\text { 276-1, DH-281, DH-282, DH-283, DH-294-2, } \\
\text { DH-295, DH-296, DH-297, DH-297-2, DH- } \\
\text { 298, DH-301, DH-302, DH-303-1, DH-303-2, } \\
\text { DH-304. }\end{array}$ \\
\hline
\end{tabular}

On the basis of visual observation of stem color, 60 genotypes were categorized into two groups. Twenty six genotypes showed green stem and 34 genotypes showed purple colouration of stem. Presented visualization showed that among the 60 genotypes, 30 genotypes bear streaks on stem and 30 genotypes bears no streaks on the stem. Similar study was also undertaken to develop stem characteristics as identification tools in thirty germplasm of fenugreek by Chauhan, (2003).
The primary branches per plant ranged from 5.2 to 14.2 (Table 2). Accordingly sixty genotypes were classified into two groups. Thirty five genotypes were classified into more branched $(\geq 10)$ group and 25 genotypes were classified as less branched $(<10)$ group. Highest primary branches were observed in DH-291 and lowest were in DH-301.

Whereas, secondary branches per plant ranged from 12.4-34.2. Accordingly sixty genotypes were classified into two groups. 
Forty one genotypes were classified as more branched $(\geq 20)$ and 19 genotypes were classified into less branched $(<20)$ group. Highest secondary branches were present in DH-261 and lowest was in DH-301. Filiz et al., (2002) also studied 43 genotypes and found that number of branches also helps in characterizing the genotypes. Similar study was also undertaken at Jobner, Rajasthan by Rajput et al., (2003) to develop branches per plant as identification tool in coriander.

From the findings it is concluded that stem characteristics and branches of coriander showed wide divergence and hence these can be consider and used as a tool for varietal identification and selection for research purpose by plant breeder and agricultural scientist.

\section{References}

Alison, M.G. and Peter, R.F., 1999. Insulin releasing and insulin like activity of the traditional anti-diabetic plant Coriander sativum (coriander). British J. Nutr. 81(3): 203-209.

Chauhan, P., 2003.Characterization and vigour assessment studies in fenugreek. Ph.D. Thesis. Department of Seed Science and Technology, CCS Haryana Agricultural University, Hisar.

Cortes-Eslava, J., Gomez-Arroyo, S. and Villalobos-Pietrini, R., 2004. Antimutagenicity of coriander (Coriandrum sativum) juice on the mutagenesis produced by plant metabolites of aromatic amines. $J$. Toxicol. Lett. 153:283-292.

Darughe, F., Barzegar, M. and Sahari, M.A., 2012. Antioxidant and antifungal activity of Coriander (Coriandrum sativum L.) essential oil in cake. Int. Food Res. J. 19(3):1253-1260.

Delaquis, P.J., Stanich, K., Girard, B. and
Mazza, G., 2002. Antimicrobial activity of individual and mixed fractions of dill, cilantro, coriander and eucalyptus essential oils. International Journal of Food Microbiology. 74:101-109.

Eidi, M., Eidi, A., Saeidi, A., Molanaei, S., Sadeghipour, A., Bahar, M. and Bahar, K., 2012. Effect of coriander seed (Coriandrum sativum L) ethanol extract on insulin release from pancreatic beta cells in streptozotocininduced diabetic rats. J. Phytother. Res. 23(3):404-406.

Filiz, A., Ahmet, M., Neset, A. and Bilal, G., 2002. Seed yield, yield components and essential oil of selected coriander lines. Journal of herbs, spices and medicinal plants. 9(2-3): 71-76.

Holland, B., Unwin, I.D. and Buss, D.H., 1991. Seed yield and essential oil of coriander lines. Vegetables, Herbs and Spices. 4: 163.

Kubo I., Fujita K., Kubo A., Nihei, K. and Ogura, T., 2004. Antibacterial activity of coriander volatile compounds against Salmonella choleraesuis. Journal of Agriculture and Food Chemistry. 52(11): 3329-3332.

Nadeem, M., Anjum, F.M., Khan, M.I., Tehseen, S., El-Ghorab, A. and Sultan, J.I., 2013. Nutritional and medicinal aspects of coriander (Coriandrum sativum L.). A review. Brit. Food J. 115(5):743-755.

Nadia, G. and Hala, K., 2012. Influence of cobalt nutrition on coriander (Cariandrum sativum L.) Herbs yield quantity and quality. J Appl. Sci. Res. 8(10):5184-5189.

Rajput, S.S., Singh, D., and Parsa, A., 2003. Variability in coriander for yield and yield components. Journal of Spices and Aromatic Crop., 12(2): 162-164.

Sunil, C., Agastian, P., Kumarappan, C. and 
Ignacimuthu, S., 2012. In vitro antioxidant, antidiabetic and antilipidemic activities of Symplocos

cochinchinensis (Lour.) S. Moore bark. J. Food Chem. Toxicol. 50(5):1547-1553.

\section{How to cite this article:}

Amit, T.P. Malik and Tehlan, S.K. 2019. Development of Identification Tools for Distinguishing Different Coriander (Coriandrum sativum L.) Genotypes Based on its Stem and Branches Characteristics. Int.J.Curr.Microbiol.App.Sci. 8(04): 594-599. doi: https://doi.org/10.20546/ijcmas.2019.804.064 